\title{
Review of: "Impacts of COVID-19 lockdowns and stimulus payments on low-income population's spending in the United States"
}

\author{
Felipa de Mello-Sampayo $^{1}$ \\ 1 ISCTE-Instituto Universitário de Lisboa
}

Potential competing interests: The author(s) declared that no potential competing interests exist.

This paper analyzes both impacts of the state lockdowns and stimulus payments on low-income population's spending. The analysis explores temporal, spatial patterns and spending across categories of 5.6 million daily transactions from 2.6 million debit cards in the U.S. using zip code data from the January 1, 2019 to May 3, 2020, from the U.S. Census data and Facteus financial transaction data. The state lockdowns started on March 19, 2020 and distributions of the stimulus payments started on April 11, 2020. The stimulus payments to mitigate the economic fallout and aid the low-income population were distributed starting from April 11, 2020, as part of a $\$ 2$ trillion economic stimulus bill (CARES Act). Eligible individuals were given $\$ 1,200$ per person (with adjusted annual gross income $<\$ 75,000$ ) or $\$ 2,400$ per married couple $(<\$ 150,000)$, and $\$ 500$ per child. The authors subtract the daily average spending at the zip code level by that of the same day in 2019, constructing the year-over-year (YoY) dollar change and YoY percentage change.

The results of difference-in-differences (DID) model to estimate the daily spending difference of the same period from 2019 to 2020, before and after the initial lockdown, and before and after the stimulus payments, indicate that the lockdowns diminished the daily average spending relative to the same period in 2019 by $\$ 3.9$ per card and $\$ 2,214$ per zip code, whereas the stimulus payments elevated the daily average spending by $\$ 15.7$ per card and $\$ 3,307$ per zip code.

The spatial analysis of the effects of lockdowns and stimulus payments focused on eight major economic regions as defined by the U.S. Department of Commerce Bureau of Economic Analysis: New England, Mideast, Southeast, Great Lakes, Plains, Rocky Mountains, Southwest, and Far West. The results of the DID model for each of the eight economic regions suggest that the net effect is strongest in Southeast (23.74) and smallest in Far West (0.514). The spatial analysis also analyzed the spending pattern across Republican and Democratic counties. The spatial association statistics (Moran-I) were calculated to examine the existence of spatial spending clusters. The results suggest that spatial heterogeneity prevailed across the U.S. and the Democratic counties displayed much more volatile dynamics than Republican ones.

The spending was classified into 26 categories from 10 major spending groups based on the Visa Merchant Category Codes (MCC). The results suggest that spending declined after the pandemic and displayed great 
heterogeneity across categories. The spending has largely transitioned from outdoor to indoor activities, and towards more economical alternatives. The increased spending on liquor and cigar, and decreased spending towards health, financial and employment services corroborate with previous studies that examines consumer behavior under emotional social exclusion, isolation, or loneliness stress.

To highlight one finding of the paper, mitigation policies designed to protect and promote the well-being of the low-income population should be specific to their location and spending categories. However, the analysis in the paper is not designed to address the welfare consequences of such policies.

Finally, it would be interesting to explore the spatial patterns of the spending using econometric techniques that would allow to estimate local DID coefficients at the county level, such as the geographic weighted regression. 